\title{
Sensitivity of bovine blastocyst gene expression patterns to culture environments assessed by differential display RT-PCR
}

\author{
David R. Natale ${ }^{1,2}$, Paul A. De Sousa ${ }^{3}$, Mark E. Westhusin ${ }^{4}$ \\ and Andrew J. Watson ${ }^{1,2 *}$ \\ ${ }^{1}$ Department of Obstetrics and Gynaecology and ${ }^{2}$ Department of Physiology, The University \\ of Western Ontario, London, Ontario, Canada; ${ }^{3}$ Roslin Institute, Roslin, Midlothian, UK; \\ ${ }^{4}$ Department of Veterinary Physiology and Pharmacology, College of Veterinary Medicine, \\ Texas A\&M University, College Station, Texas, USA
}

\begin{abstract}
The use of culture media to support the development of preimplantation embryos to the blastocyst stage is often associated with detrimental effects on normal development. These effects have been uncovered largely by investigating the phenotypic abnormalities displayed by fetuses and newborns derived from cultured preimplantation embryos. Research to understand the impact of culture on the embryonic developmental programme has focused on embryo metabolism, gene expression and genomic imprinting. We have used differential display RT-PCR to examine culture influences on global transcript pools in bovine embryos. Others have examined culture influences on candidate 'marker genes' in cultured murine, ovine and bovine embryos. These studies have demonstrated that culture conditions influence the amount of marker gene transcripts and downregulate or induce the expression of novel genes during early development. Optimized defined culture media maintain embryonic gene expression patterns closely resembling those displayed by embryos derived in vivo. Preimplantation mammalian embryos display an impressive capacity to respond to the pressures that suboptimal culture environments place upon them. However, this plasticity operates within a defined range of tolerances. Continued research using molecular techniques will lead to increased understanding of developmental mechanisms causing culture-related phenotypic abnormalities in postimplantation embryos.
\end{abstract}

Steady progress in developing improved culture conditions for preimplantation embryos from a variety of mammalian species has occurred over the past 40 years (Gardner, 1994; Edwards, 1997). The rate of progress has intensified in the last 10-15 years, resulting in the characterization of effective defined or semi-defined media for early embryos in a range of species, including mice (potassium simplex optimized medium, KSOMaa; Ho et al., 1995), hamsters (hamster embryo culture medium 10, HECM-10; Lane et al., 1999), sheep and cows (citrate supplemented synthetic oviduct fluid medium, cSOFMaa; Gardner 1994; Keskintepe et al., 1995; Keskintepe and Brackett, 1996; Walker et al., 1996; Watson et al., 2000), pigs (Machaty et al., 1998) and, most recently, humans (Gardner et al., 1998; Gardner and Schoolcraft, 1999). Preimplantation mammalian embryos display an impressive capacity to respond

*Correspondence

Email: andrew.watson@med.uwo.ca

This article is based on a presentation given at the British Society of Animal Science symposium 'Early Regulation of Mammalian Development' held in Aberdeen in September 2000. positively to the pressures that suboptimal culture conditions place upon them (Ho et al., 1994, 1995; Niemann and Wrenzycki, 2000; Watson et al., 2000). The embryo can (at least partially) compensate for missing components or offset the presence of deleterious components by adjusting its developmental programme (Niemann and Wrenzycki, 2000). However, this plasticity operates within a defined range of tolerances; the vital components of the maternal environment that are required to support early development are yet to be defined, as are their mechanisms and interactions with one another. In addition, current media are known to be suboptimal because cultured embryos from all species (although to a lesser extent in mice) result in reduced pregnancy rates after embryo transfer, and are prone to metabolic and growth disorders that may originate in the culture conditions during preimplantation development (Sinclair et al., 1999; Barker et al., 2000; Boerjan et al., 2000).

These concerns have prompted a great effort to understand how early embryos adjust their developmental programme to compensate for exposure to suboptimal culture environments (for a review, see Niemann and 
Wrenzycki, 2000). Approaches in this research area have included studies comparing expression of different marker genes and also variations in embryo metabolism between preimplantation embryos derived in vitro and in vivo. We have addressed these concerns by applying differential display (DD)-RT-PCR to assess culture influences on embryonic gene expression patterns. DD-RT-PCR provides an unbiased method to compare mRNA pools from two or more samples (Liang and Pardee, 1992; Zimmerman and Schultz, 1994; DeSousa et al., 1999) and can result in the identification of new gene products. Our objectives were to compare gene expression patterns in bovine blastocysts cultured from the one-cell stage in defined conditions (cSOFMaa and KSOMaa) versus non-defined conditions (TCM-199 + serum and co-culture) and to identify embryonic gene products that may be subject to culture influences. This review summarizes current understanding of culture influences on embryonic gene expression patterns and relates them to our new findings on the global effects of culture environment on embryonic gene expression patterns.

\section{Programme of gene expression during the first week of mammalian development}

Estimates of mRNA content in cultured bovine embryos indicate that the content declines between the mature oocyte and the morula stage, and increases again at the blastocyst stage (Bilodeau-Goeseels and Schultz, 1997a,b). This pattern of mRNA loss and re-accumulation mimics the pattern observed in mice, although the increase occurs by the eight-cell stage in mice, possibly as a result of the earlier onset of embryonic gene activation in this species (Piko and Clegg, 1982). DD-RT-PCR revealed the decline in maternal transcripts and renewal of embryonic transcripts that occur after full activation of the bovine embryonic genome (Natale et al., 2000). The first variation from the oogenetic cDNA banding pattern was observed in two- to five-cell bovine embryos. The principal transition from an oogenetic (maternal) to embryonic gene transition occurred at the sixto eight-cell stage. This transition in cDNA banding pattern continued to the blastocyst stage. These transitions in embryonic cDNA banding patterns revealed by DD-RT-PCR are in agreement with the timing of the oogeneticembryonic transition described for bovine embryos by other investigators (Plante et al., 1994; Viuff et al., 1996, 1998; Memili and First, 1998; Memili et al., 1998). The decreased relative number of oocyte cDNA bands observed throughout bovine pre-attachment development probably reflects the degradation of maternal mRNAs (deadenylation) before activation of the embryonic genome (Paynton et al., 1988; Brevini-Gandolfi et al., 1999).

In bovine embryos, the full activation of the zygotic genome occurs by the 8-16-cell stage as evidenced by $\left[{ }^{3} \mathrm{H}\right]$ uridine incorporation into nuclei and nucleoli at the eight-cell stage, and major changes in the ultrastructure of blastomere nucleoli and the pattern of protein synthesis (for reviews, see Telford et al., 1990; De Sousa et al., 1998).
Studies investigating $\left[{ }^{3} \mathrm{H}\right]$ uridine uptake in two- to four-cell embryos revealed that transcriptional activity can be detected earlier than the 8-16-cell stage (Plante et al., 1994; Viuff et al., 1996). Other studies using transcriptional inhibitors and $\left[{ }^{3} \mathrm{H}\right]$ uridine incorporation into RNA supported these findings (Memili and First, 1998; Memili et al., 1998; Viuff et al., 1998). However, development proceeds to the eight-cell stage in the presence of $\alpha$-amanitin (Liu and Foote, 1997). These findings are similar to those in other mammalian species (reviewed in Telford et al., 1990; De Sousa et al., 1998). In rabbits, in which the oogeneticembryonic transition occurs at the 8-16-cell stage, transcriptional activity occurs by the two-cell stage, although the first four cleavages occur in the presence of $\alpha$-amanitin (reviewed in Telford et al., 1990). Similarly, although oogeneticembryonic transition is complete in mice by the two-cell stage, zygotic transcription occurs first in male pronuclei (Bouniol et al., 1995, Christians et al., 1995). Extensive studies on early mouse embryos have characterized the degradation of maternal RNAs after fertilization by measuring mRNA de-adenylation (Paynton et al., 1988).

Natale et al. (2000) also observed that cDNA banding patterns are largely conserved from the 8-16-cell stage through to the blastocyst stage in bovine embryos. Blastocyst formation is dependent upon transcription up to $84 \mathrm{~h}$ after hCG in mice, which is a time of development just preceding blastocyst formation (Kidder and McLachlin, 1985). In bovine embryos, more of the blastocyst mRNAs are detectable first at the 8-16-cell stage and only a comparatively small number of unique mRNAs are present in blastocyst cDNA samples (Natale et al., 2000).

\section{Influence of culture environments on embryonic gene expression}

Concerns regarding effects of culture on embryonic gene expression patterns were first raised in studies of early mouse embryos (for a review, see Niemann and Wrenzycki, 2000; Table 1). For example, gene transfection studies using a gene construct encoding the heat shock protein $(\mathrm{Hsp}) 70.1$ coupled to sequences encoding a luciferase reporter gene demonstrated that reporter gene activity is up to 15 times higher in embryos derived in vitro than that observed in embryos derived in vivo (Christians et al., 1995). Similar approaches have demonstrated that in vitro derived embryos produce seven times less platelet activating factor (PAF) than in vivo derived embryos ( $\mathrm{O}^{\prime}$ Neill, 1997). PAF signalling is crucial for regulating intracellular $\mathrm{Ca}^{2+}$, which is a fundamental regulator of cell physiology. Additional studies have examined variations in the expression of mRNAs encoding a wide variety of gene products, including actin, glyceraldehyde-3-phosphate dehydrogenase, Na/K-ATPase, Sp1, TATA box binding protein (TBP), insulin-like growth factor (IGF)-I and -II and IGF-I and -II receptors, in murine preimplantation embryos cultured in KSOMaa or Whitten's medium compared with expression in in vivo derived embryos (Ho et al., 1994, 1995). Only a single transcript, 
Table 1.

(a) Influence of culture conditions on gene expression in mouse embryos

\begin{tabular}{|c|c|c|c|}
\hline Gene & Versus in vivo & $\begin{array}{c}\text { KSOMaa } \\
\text { versus in vivo }\end{array}$ & $\begin{array}{l}\text { Whitten's } \\
\text { versus in vivo }\end{array}$ \\
\hline $\begin{array}{l}\text { Heat shock protein } 70.1 \\
\text { Platelet activating factor }\end{array}$ & $\begin{array}{l}15 \times \text { increase }^{a} \\
7 \times \text { increase }^{b}\end{array}$ & & \\
\hline $\begin{array}{l}\text { Actinc } \\
\text { Glyceraldehyde-3-phosphate dehydrogenase }^{c} \\
\text { Na/K-ATPase } \\
\text { Sp1 }{ }^{\mathrm{c}} \\
\text { TATA box binding protein }^{\mathrm{C}} \\
\text { Insulin-like growth factor Ic } \\
\text { Insulin-like growth factor II } \\
\text { Insulin-like growth factor I receptor } \\
\text { Insulin-like growth factor II receptor }\end{array}$ & & $\begin{array}{l}\mathrm{NC} \\
\mathrm{NC} \\
\mathrm{NC} \\
\mathrm{NC} \\
\text { Increased } \\
\mathrm{NC} \\
\mathrm{NC} \\
\mathrm{NC} \\
\mathrm{NC}\end{array}$ & $\begin{array}{l}\mathrm{NC} \\
\text { Decreased } \\
\mathrm{NC} \\
\mathrm{NC} \\
\text { Decreased } \\
\text { Decreased } \\
\text { Decreased } \\
\text { Decreased } \\
\text { Decreased }\end{array}$ \\
\hline
\end{tabular}

(b) Influence of culture conditions on gene expression in bovine embryos

\begin{tabular}{lcc}
\hline Gene & In vitro versus in vivo & Serum versus PVA \\
\hline Connexin 43 & Decreased & \\
Desmocollin & $\mathrm{NC}$ & Decreased $^{f}$ \\
Plakophilin & $\mathrm{NC}$ & Decreased $^{f}$ \\
Glucose transporter I & $\mathrm{NC}$ & Decreased $^{\mathrm{e}}$ \\
Poly-A-polymerase & $\mathrm{NC}$ & Decreased $^{\mathrm{f}}$ \\
Heat shock protein 70.1 & $\mathrm{NC}$ & Decreased $^{\mathrm{e}}$ \\
Trophoblast protein & $\mathrm{NC}^{\mathrm{e}}$ & Decreased $^{f}$ \\
\hline
\end{tabular}

${ }^{\mathrm{a} C h r i s t i a n s}$ et al.,1995.

b'O'Neill, 1995.

cHo et al., 1995.

defWrenzycki et al., 1996, 1998,1999.

KSOMaa: potassium simplex optimized medium; NC: no change; PVA: polyvinyl alcohol.

that encoding TATA box binding protein, was found to vary significantly between the embryos cultured in KSOMaa and those derived in vivo. However, eight of these gene products were observed to be present at significantly different amounts in embryos cultured in Whitten's medium compared with either embryos cultured in KSOMaa or embryos derived in vivo (Ho et al., 1994, 1995). These studies emphasize that culture environments can influence embryonic gene expression patterns profoundly and that current media, such as KSOMaa, effectively provide the early mouse embryo with an opportunity to express important early genes at normal levels. The influences of culture media on embryonic gene expression patterns do not extend exclusively from the protein or amino acid supplements; ion concentrations can also have important influences on gene expression. Ho et al. (1994) compared RNA synthesis and expression of genes from the IGF family in murine embryos cultured in simplex optimized medium composed of either 85 or $125 \mathrm{mmol} \mathrm{NaCl}^{-1}$. Earlier studies had indicated that $85 \mathrm{mmol} \mathrm{NaCl} \mathrm{I^{-1 }}$ was linked to higher rates of development in vitro and higher rates of protein synthesis (Anbari and Schultz, 1993; Biggers et al., 1993).
Similarly, it was discovered that RNA synthesis rates were reduced by $20 \%$ and that RNAs of IGF family members were also reduced significantly in embryos cultured in medium with $125 \mathrm{mmol} \mathrm{NaCl} \mathrm{l}^{-1}$ (Ho et al., 1994). Additional studies have reported that these effects of culture on gene expression extend to other gene families such as laminins and glucose transporters (Shim et al., 1996).

Cultured bovine embryos also display a very different pattern of gene expression than do embryos derived in vivo (Table 1b). For example, transcripts encoding connexin 43 (Cx43) were detected in in vivo derived bovine morulae and blastocysts but not in bovine blastocysts produced in vitro and cultured in TCM-199 medium + oestrous cow serum (Wrenzycki et al., 1996). The precise role of Cx43 in mediating early development is still uncertain as Cx43 murine knockouts progress through development to birth without impairment. However, it is clear that gap junctional coupling is a fundamental event that regulates cell-cell communication and thus it is a concern that such an important gene family member is absent in cultured embryos (Niemann and Wrenzycki, 2000). In a second study in which the expression of ten 'marker' genes was 


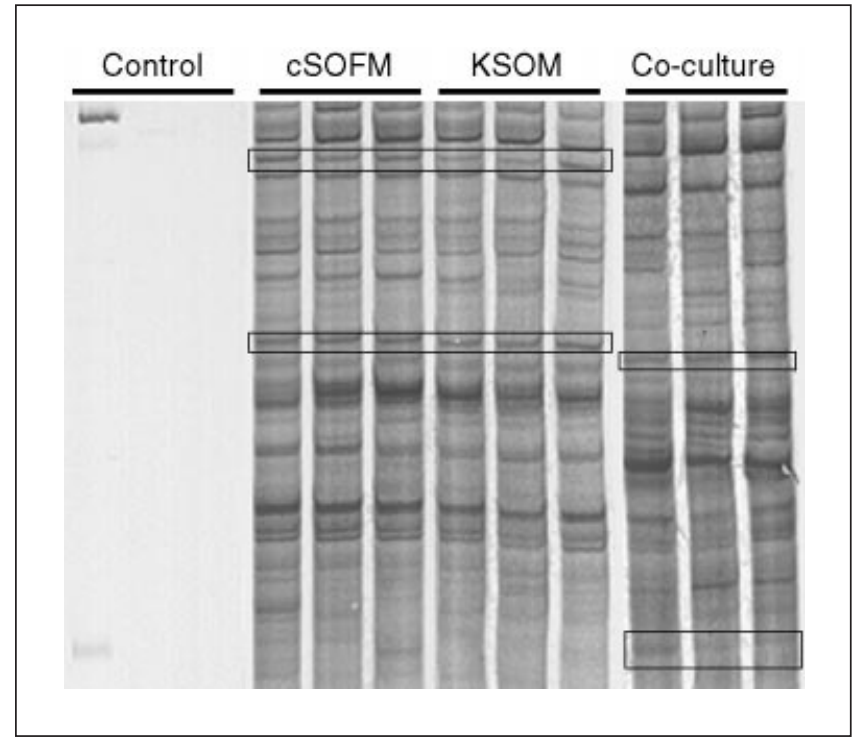

Fig. 1. cDNA banding patterns from a section of a typical differential display (DD)-RT-PCR applied to bovine blastocysts derived from culture of zygotes to the blastocyst stage in two different defined culture media (citrate supplemented synthetic oviduct fluid medium (cSOFM) and potassium simplex optimized medium (KSOM)) and one co-culture/serum supplemented culture system (Co-culture). Boxed regions indicate examples of cDNA bands considered to be differentially expressed. Negative control for DD-RT-PCR is also shown.

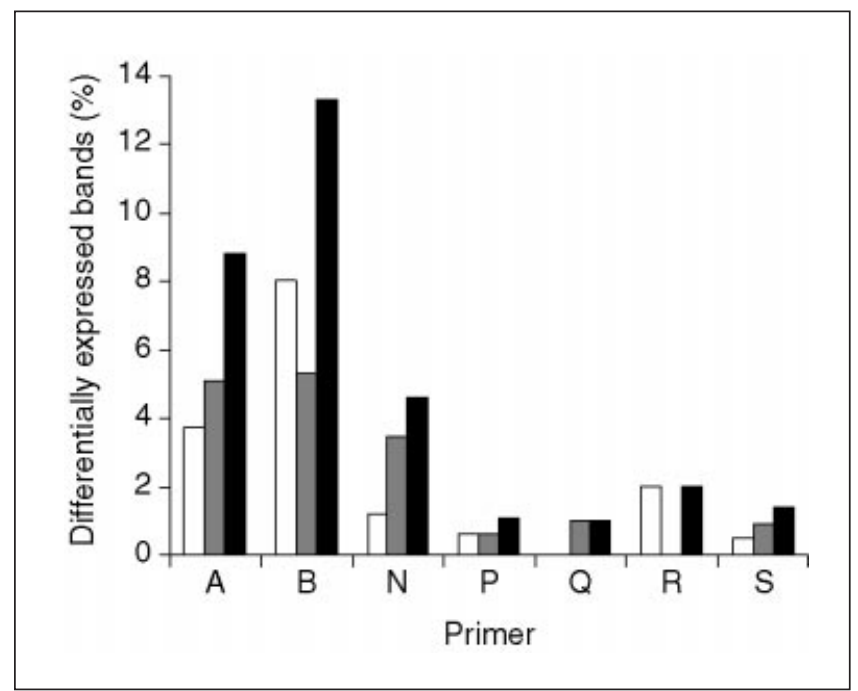

Fig. 2. Percentage differences in cDNA banding patterns produced by differential display (DD)-RT-PCR on embryos cultured to the blastocyst stage in TCM-199 + 10\% NCS + Coculture $(\square)$ versus those cultured to the blastocyst stage in citrate supplemented synthetic oviduct fluid medium (cSOFMaa) or potassium simplex optimized medium (KSOMaa) ( $\square$; primers A and B) or those cultured to the blastocyst stage in cSOFMaa ( $\square$; primers $\mathrm{N}, \mathrm{P}, \mathrm{Q}, \mathrm{R}$ and $\mathrm{S}$ ). Results represent the number of bands specific to each treatment as a percentage of the average total number of conserved bands counted in triplicate lanes for each

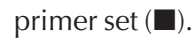

compared between in vivo derived bovine embryos and in vitro derived embryos cultured in TCM-199 + BSA, only Cx43 was differentially expressed, indicating that cultured bovine blastocysts are deficient in this gene product (Wrenzycki et al., 1998). No other differences in gene expression in these two groups of embryos were reported in this study, which included an examination of desmocollin, plakophilin, glucose transporter 1, polyA polymerase, Hsp 70.1 and trophoblast protein transcripts (Wrenzycki et al., 1998). Another study by the same group reported that supplementing the medium with either serum or polyvinyl alcohol (PVA) influenced the expression patterns of these genes in bovine embryos cultured in vitro (Wrenzycki et al., 1999). Only Hsp 70.1 was higher in the serum supplemented group, whereas the PVA supplemented group displayed increased concentrations of the other gene products, especially from the 8-16-cell stage to the blastocyst stage (Wrenzycki et al., 1999). The influences of culture on gene expression patterns can arise as early as oocyte maturation as a significant decline in Na/K-ATPase $\alpha 1$ subunit mRNAs and in cyclin A mRNAs was observed when bovine cumulus-oocytes complexes (COCs) were matured in maturation medium devoid of amino acids (Watson et al., 2000). These effects were also reflected by a reduced developmental frequency to the blastocyst stage by COCs matured in amino acid deficient medium (Watson et al., 2000).

\section{Characterization of culture environment influence on bovine embryonic gene expression by DD-RT-PCR}

It has been difficult to measure the full impact of studies that report culture-sensitive influences on embryonic gene expression patterns as, to date, none has been able to couple an analysis of gene expression with an exploration of the consequences to implantation and pregnancy frequencies. This deficiency of data is a result of the extreme technical challenge associated with coupling embryo biopsy and mRNA transcript analysis with embryo transfer studies. However, of greater concern is the absence of a precise list of useful 'marker' genes. As discussed above, only a few genes are influenced by culture environments and, if this approach is to emerge as a practical tool for assessing culture efficacy and embryo health, the list of marker genes must be increased markedly. We have initiated this process by applying DD-RT-PCR analysis to characterize culture-sensitive gene expression patterns in bovine embryos. In our analysis, mRNA pools isolated from blastocysts produced under non-defined (TCM-199 + serum + co-culture) and defined (cSOFMaa and KSOMaa) conditions were screened by DD-RT-PCR using seven different primer combinations.

A section of a typical DD-RT-PCR gel resulting from comparing mRNA profiles of bovine blastocysts cultured in both defined (cSOFMaa and KSOMaa) and non-defined (TCM-199 + serum + co-culture) conditions is shown 
Table 2. Sequence screening of differentially expressed cDNAs

\begin{tabular}{lcll}
\hline Treatment & Size $(\mathrm{bp})$ & Base homology $(\%)$ & \multicolumn{1}{c}{ Sequence similarity } \\
\hline $\begin{array}{l}\text { Defined } \\
\text { Co-culture }\end{array}$ & 365 & $143 / 159(89.9 \%)$ & AC008908 Homo sapiens chromosome 5 clone CTD-2265E4 \\
& 260 & $138 / 152(90 \%)$ & BTA237934 Bos taurus partial STAT5B gene \\
Co-culture & 355 & $131 / 146(89 \%)$ & AW313804 9371 MARC 4Bov Bos taurus cDNA \\
Defined & 305 & $45 / 59(93 \%)$ & C18327 Human placental cDNA \\
Defined & 568 & $168 / 187(90 \%)$ & AF008307 Bos taurus neutrophil beta-defensin 4 (BNBD4) gene \\
Co-culture & 407 & $284 / 321(86 \%)$ & AW313642 9044 MARC 1 Bov Bos taurus CDNA \\
Co-culture & 402 & $209 / 249(84 \%)$ & AC027313 Homo sapiens chromosome 5 clone CTC-278L1 \\
\hline
\end{tabular}

(Fig. 1). In these experiments, the results were analysed by first determining a mean \pm SE for the total bands that were conserved among the triplicate reactions for blastocysts produced under each culture regimen. Each primer set combination defines and amplifies a unique subset of embryonic mRNAs. The total number of cDNAs that a given primer set may amplify is unique but consistent between experimental replicates. The cDNA banding patterns were analysed to determine the number of conserved and unique bands that were present between each blastocyst culture sample and for each primer set combination (Fig. 2). The cDNA banding pattern did not vary between blastocysts produced in the two defined media (cSOFMaa versus KSOMaa). However, when cDNA banding patterns were compared between the defined and non-defined (TCM-199 + co-culture) treatments, primer A revealed five cDNA bands and primer $B$ revealed nine cDNA bands specific to blastocysts cultured under non-defined conditions. In addition, primer $A$ revealed seven specific cDNA bands and primer B revealed six specific cDNA bands in blastocyst samples cultured in defined conditions (cSOFMaa and KSOMaa). This variation in banding pattern between embryos cultured under defined and serum supplemented conditions was also observed when the five additional primer sets were used. However, fewer banding variations were observed with these primer sets. These results indicate that most of the differences in embryonic gene expression patterns will be found between serum-supplemented and serum-free culture conditions. The results also imply that each type of culture environment exerts a unique influence upon the early embryo, resulting in a distinct gene expression pattern for embryos cultured in each medium.

In total, 41 differentially expressed cDNA bands were isolated from this analysis, of which 21 were specific to blastocysts produced under non-defined culture conditions and the remaining 20 cDNA bands were confined to blastocysts produced under defined conditions. The 41 cDNA bands were isolated from a total of 1091 bands that were displayed in all of the samples analysed in this study. This figure represents 3.8\% of all cDNA bands displaying an apparent sensitivity to the culture environment.

\section{Differentially expressed mRNAs}

It is necessary to clone and sequence each product and confirm its differential expression to proceed further with the analysis of the culture-sensitive gene products. We have initiated this process by sequencing 20 of the 41 differentially expressed cDNA bands. Ten of the products were detected only in the defined media and the remaining ten were observed only in the co-culture non-defined treatment. Of the 20 products, seven displayed a significant homology to cDNA sequences found in Genbank (Table 2). Most of these products represent DNA sequences characterized recently that encode genes of unknown function. Further research is required to determine the expression of these gene products during early development, to confirm their differential expression to specific embryo culture treatments, and subsequently to examine the functional significance of their culture-sensitive gene expression on early development.

In conclusion we have determined that blastocysts cultured under non-defined and defined culture conditions display different mRNA transcript patterns. These differences may not reflect variations in embryo health or developmental potentials but instead may reflect the overall plasticity that the embryo can exhibit to compensate for a suboptimal culture environment. The frequency of blastocyst formation is similar for zygotes placed into either of the culture systems used in the study described. It is predicted that the different patterns of mRNAs displayed by blastocysts cultured in these systems reflect the response of the embryos to different suboptimal environments rather than inferring a decline in overall embryonic health. The embryo may attempt to respond to a suboptimal environment by adjusting its gene expression pattern, and by investigating these responses it may be possible to improve understanding of the genetic programme controlling the first week of development and also to design improved culture media. DD-RT-PCR is an effective method for investigating overall influences on embryonic mRNA pools. Several new putative culture-sensitive embryonic mRNAs have been characterized initially. These products may be of assistance 
in contributing to an effective marker gene list once their roles are defined.

The authors wish to thank John Looye, Lisa Barcroft and Anita Caveney for assistance with bovine embryo culture and application of DD-RT-PCR methods. They are also grateful for the assistance of ABEL laboratories (University of Guelph). This research was supported by a National Sciences and Engineering Research Council of Canada (NSERC) operating grant to A. J. Watson and was carried out as part of the National Co-operative Program on Nonhuman in Vitro Fertilization and Preimplantation Development supported by NIH Cooperative Agreement U01HD34580 to M. E. Westhusin and A. J. Watson.

\section{References}

Key references are identified by asterisks.

Anbari K and Schultz RM (1993) Effect of sodium and betaine in culture media on development and relative rates of protein synthesis in preimplantation mouse embryos Molecular Reproduction and Development 35 24-28

Barker DJP (2000) In utero programming of cardiovascular disease Theriogenology 53 555-574

Biggers JD, Lawitts JA and Lechene CP (1993) The protective action of betaine on the deleterious effects of $\mathrm{NaCl}$ on preimplantation mouse embryos in vitro. Molecular Reproduction and Development 34 380-390

Bilodeau-Goeseels S and Schultz GA (1997a) Changes in the relative abundance of various housekeeping gene transcripts in in vitroproduced early bovine embryos Molecular Reproduction and Development 47 413-420

Bilodeau-Goeseels S and Schultz GA (1997b) Changes in ribosomal ribonucleic acid content within in vitro-produced bovine embryos Biology of Reproduction 56 1323-1329

Boerjan ML, den Das JHG and Dieleman SJ (2000) Embryonic origins of health: long-term effects of IVF in human and livestock Theriogenology 53 537-547

Bouniol C, Nguyen E and Debey P (1995) Endogenous transcription occurs at the 1-cell stage in the mouse embryo Experimental Cell Research $\mathbf{2 1 8}$ $57-62$

Brevini-Gandolfi TAL, Favetta LA, Mauri L, Luciano AM, Cillo F and Gandolfi $\mathbf{F}$ (1999) Changes in poly(A) tail length of maternal transcripts during in vitro maturation of bovine oocytes and their relation with developmental competence Molecular Reproduction and Development 52 427-433

Christians E, Campion E, Thompson EM and Renard J-P (1995) Expression of the HSP 70.1 gene, a landmark of early zygotic gene activity in the mouse embryo, is restricted to the first burst of transcription Development 112 113-122

De Sousa PA, Watson AJ, Schultz GA and Bilodeau-Goeseels S (1998) Oogenetic and zygotic gene expression directing early bovine embryogenesis: a review Molecular Reproduction and Development $\mathbf{5 1}$ 112-121

*De Sousa PA, Winger Q, Hill J, Jones K, Watson AJ and Westhusin ME (1999) Reprogramming of fibroblast mRNA expression following nuclear transfer in bovine embryos Cloning 1 63-69

Edwards RG (1997) Recent scientific and medical advances in assisted human conception International Journal of Developmental Biology 41 255-262

Gardner DK (1994) Mammalian embryo culture in the absence of serum or somatic cell support Cell Biology International 18 1163-1179

Gardner DK and Schoolcraft WB (1999) Culture and transfer of human blastocysts Current Opinion in Obstetrics and Gynaecology 11 307-311

Gardner DK, Schoolcraft WB, Wagley L, Schlenker T, Stevens J and Hesla J (1998) A prospective randomised trial of blastocyst culture and transfer in in vitro fertilization Human Reproduction 13 3434-3440

*Ho Y, Doherty AS and Schultz RM (1994) Mouse preimplantation development in vitro: effect of sodium concentration in culture media on RNA synthesis and accumulation and gene expression Molecular Reproduction and Development 38 131-141

*Ho Y, Wigglesworth K, Eppig JJ and Schultz RM (1995) Preimplantation development of mouse embryos in KSOM: augmentation by amino acids and analysis of gene expression Molecular Reproduction and Development 41 232-238

Kidder GM and McLachlin JR (1985) Timing of transcription and protein synthesis underlying morphogenesis in preimplantation mouse embryos Developmental Biology 112 265-275

Keskintepe L and Brackett BG (1996) In vitro developmental competence of in vitro matured bovine oocytes fertilized and cultured in completely defined media Biology of Reproduction 55 333-339

Keskintepe L, Burnley CA and Brackett BG (1995) Production of viable bovine blastocysts in defined in vitro conditions Biology of Reproduction 52 1410-1417

Lane M, Ludwig TE and Bavister BD (1999) Phosphate induced developmental arrest of hamster two-cell embryos is associated with disrupted ionic homeostasis Molecular Reproduction and Development $\mathbf{5 4}$ 410-417

Liang P and Pardee AB (1992) Differential display of eukaryotic messenger RNA by means of the polymerase chain reaction Science 257 967-971

Liu Z and Foote RH (1997) Effects of amino acids and $\alpha$-amanitin on bovine embryo development in a simple protein-free medium Molecular Reproduction and Development 46 278-285

Machaty Z, Day BN and Prather RS (1998) Development of early porcine embryos in vitro and in vivo. Biology of Reproduction 59 451-455

Memili E and First NL (1998) Developmental changes in RNA polymerase II in bovine oocytes, early embryos and effect of $\alpha$-amanitin on embryo development Molecular Reproduction and Development 51 381-389

Memili E, Dominko T and First NL (1998) Onset of transcription in bovine oocytes and preimplantation embryos Molecular Reproduction and Development 51 36-41

Natale DR, Kidder GM, Westhusin ME and Watson AJ (2000) Assessment by differential display-RT-PCR of mRNA transcript transitions and $\alpha$ amanitin sensitivity during bovine preattachment development Molecular Reproduction and Development 55 152-163

Niemann H and Wrenzycki C (2000) Alterations of expression of developmentally important genes in preimplantation bovine embryos by in vitro culture conditions: implications for subsequent development Theriogenology 53 21-34

O'Neill C (1997) Evidence for the requirement of autocrine growth factors for development of mouse preimplantation embryos in vitro. Biology of Reproduction 56 229-237

Paynton BV, Rempel R and Bachvarova R (1988) Changes in state of adenylation and time course of degradation of maternal mRNAs during oocyte maturation and early embryonic development in the mouse Developmental Biology 129 304-314

Piko L and Clegg KB (1982) Quantitative changes in total RNA, total poly(A), and ribosomes in early mouse embryos Developmental Biology $\mathbf{8 9}$ $362-378$

Plante L, Plante C, Shepherd DL and King WA (1994) Cleavage and ${ }^{3} \mathrm{H}$ uridine incorporation in bovine embryos of high in vitro developmental potential Molecular Reproduction and Development 39 375-383

Shim C, Know HB and Kim K (1996) Differential expression of laminin chain-specific mRNA transcripts during mouse preimplantation development Molecular Reproduction and Development 44 44-55

Sinclair KD, McEvoy TG, Maxfield EK, Maltin CA, Young LE, Wilmut L, Broadbent PJ and Robinson JJ (1999) Aberrant fetal growth and development after in vitro culture of sheep zygotes Journal of Reproduction and Fertility 116 177-186

Telford NA, Watson AJ and Schultz GA (1990) Transition from maternal to embryonic control in early mammalian development: a comparison of several species Molecular Reproduction and Development 26 90-100

Viuff D, Avery B, Greve T, King WA and Hyttel P (1996) Transcriptional activity in in vitro produced bovine two- and four-cell embryos Molecular Reproduction and Development 43 171-179

Viuff D, Hyttel P, Avery B, Vajta G, Greve Y, Callesen H and Thomsen PD (1998) Ribosomal ribonucleic acid is transcribed at the 4-cell stage in in vitro-produced bovine embryos Biology of Reproduction 59 626-631 
Walker SK, Hill JL, Kleemann DO and Nancarrow CD (1996) Development of ovine embryos in synthetic oviductal fluid containing amino acids at oviductal fluid concentrations Biology of Reproduction 55 703-708

Watson AJ, De Sousa P, Caveney A, Barcroft LC, Natale D, Urquhart J and Westhusin ME (2000) Impact of bovine oocyte maturation media on oocyte transcript levels, blastocyst development, cell number and apoptosis Biology of Reproduction 62 355-364

Wrenzycki C, Herrmann D, Carnworth JW and Niemann H (1996) Expression of the gap junction gene connexin43 (Cx43) in preimplantation bovine embryos derived in vitro and in vivo. Journal of Reproduction and Fertility 108 17-24
*Wrenzycki C, Herrmann D, Carnworth JW and Niemann H (1998) Expression of mRNA from developmentally important genes in preimplantation bovine embryos produced in TCM supplemented with BSA Journal of Reproduction and Fertility 112 387-398

*Wrenzycki C, Herrmann D, Carnworth JW and Niemann H (1999) Alterations in the relative abundance of gene transcripts in preimplantation bovine embryos cultured in medium supplemented with either serum or PVA Molecular Reproduction and Development 53 8-18

Zimmerman JW and Schultz RM (1994) Analysis of gene expression in the preimplantation mouse embryo: use of mRNA differential display Proceedings National Academy of Sciences USA 91 5456-5460 